\title{
Comparison of efficacy, safety, and predictability of laser in situ keratomileusis using two laser suites
}

This article was published in the following Dove Press journal:

Clinical Ophthalmology

24 August 2016

Number of times this article has been viewed

\section{Alexandra Meidani ${ }^{1-3}$ Chara Tzavara ${ }^{3}$}

'Hypervision Laser Centre, ${ }^{2}$ Eye Day Clinic, ${ }^{3}$ Department of Hygiene, University of Athens Medical School, Centre for Health Services Research, Epidemiology and Medical Statistics, Athens, Greece
Correspondence: Alexandra Meidani Athens Medical Centre, 5-7 Distomou Str, Marousi, Athens 15125, Greece Tel +30 2l 06157228

Email alex_P_mei@yahoo.com
Purpose: The main aim of this study was to compare the efficacy, safety, and predictability of femtosecond laser-assisted in situ keratomileusis performed by two different laser suites in the treatment of myopia for up to 6 months.

Methods: In this two-site retrospective nonrandomized study, myopic eyes that underwent laser-assisted in situ keratomileusis using IntraLase FS $60 \mathrm{kHz}$ formed group 1 and those using WaveLight FS200 femtosecond laser system formed group 2. Ablation was performed with Visx Star S4 IR and WaveLight EX500 Excimer lasers, respectively, in groups 1 and 2. Both groups were well matched for age, sex, and mean level of preoperative refractive spherical equivalent (MRSE). Uncorrected distance visual acuity, corrected distance visual acuity, and MRSE were evaluated preoperatively and at 1 week, 1 month, and 6 months after treatment.

Results: Fifty-six eyes of 28 patients were included in the study. At 6-month follow-up postop, $78.6 \%$ of eyes in group 1 and $92.8 \%$ of eyes in group 2 achieved an uncorrected distance visual acuity of $20 / 20$ or better $(P=0.252) .35 .7 \%$ and $50 \%$ in group 1 and group 2 , respectively, gained one line $(P=0.179)$. No eye lost lines of corrected distance visual acuity. Twenty-five eyes in group $1(92.7 \%)$ and 27 eyes in group $2(96.3 \%)$ had MRSE within $\pm 0.5 \mathrm{D}$ in the 6-month follow-up $(P>0.999)$. The mean efficacy index at 6 months was similar in group 1 and group 2 (mean $1.10 \pm 0.12$ [standard deviation] vs $1.10 \pm 0.1)(P=0.799)$. The mean safety index was similar in group 1 and group 2 (mean $1.10 \pm 0.10$ [standard deviation] vs $1.10 \pm 0.09)(P=0.407)$.

Conclusion: The outcomes were excellent between the two laser suites. There were no significant differences at 6-month follow-up postop between the two laser systems.

Keywords: myopia, LASIK, IntraLase FS 60 kHz, WaveLight FS200, Visx Star S4 IR, WaveLight EX500

\section{Introduction}

It is evidenced that femtosecond laser-assisted in situ keratomileusis (LASIK) is an established, effective, and safe technique used to treat myopia and myopic astigmatism. ${ }^{1-9}$ The creation of a flap thickness ranging from 100 to $130 \mu \mathrm{m}$ with a standard deviation of 10-15 $\mu \mathrm{m}$ using femtosecond lasers is considered state of the art. ${ }^{2,3,7}$ Femtosecond laser surgery offers a safety advantage over microkeratome-based LASIK procedures. ${ }^{8-14}$ The accurate spot positioning, spacing, and optimized spatial and temporal scan sequences of the laser spot, as well as the possibility of having variation of flap width, flap depth, hinge width, variable diameter, and side-cut angles lead to better surgical results. ${ }^{9-15}$

Commercially available femtosecond lasers in refractive surgery are the IntraLase (Abbott Medical Optics Inc, Santa Ana, CA, USA), which was the first femtosecond laser introduced in the US in 2001; ${ }^{11}$ the Technolas Femtosecond Workstation, formerly known as Femtec, by Technolas Perfect Vision (Munich, Germany); the FEMTO LDV 
by Ziemer Ophthalmic Systems (Port, Switzerland), introduced in the late $2005 ;^{3}$ the Visumax by Carl Zeiss Meditec AG (Jena, Germany), introduced in the fall of $2006 ;^{3}$ and the WaveLight FS200 (Alcon Laboratories, Inc., Fort Worth, TX, USA) that received US Food and Drug Administration approval in $2010 .^{5}$

There are two different concepts in photodisruption process, either high pulse energy and low pulse frequency, such as IntraLase and Femtec, or low pulse energy and high pulse frequency, such as FEMTO LDV and WaveLight FS200. ${ }^{3}$ Higher-energy lasers operate in the microjoule $(\mu \mathrm{J})$ range and repetition frequencies are in the kilohertz $(\mathrm{kHz})$ range. In these systems, each laser spot creates an expansile bubble that facilitates the disruption process by allowing for a greater separation of laser pulses. On the other hand, the lowerenergy lasers operate in the nanojoule range $(\mathrm{nJ})$ and require closer spacing of the laser pulses and repetition frequencies are in the megahertz $(\mathrm{MHz})$ range. ${ }^{3}$ In both methods, the laser spots create a potential geometric shape or plane that is then manually dissected to complete the process.

IntraLase $60 \mathrm{kHz}$ system is a very commonly used laser of high pulse energy and low pulse frequency, with a wavelength of 1,053 nm. ${ }^{3}$ WaveLight FS200 femtosecond laser system is a low-energy and high pulse frequency laser that emits laser pulses with duration of $350 \mathrm{fs}$ at a wavelength of $1,050 \mathrm{~nm}$ and pulse repetition rate of $200 \mathrm{kHz} .{ }^{7}$ IntraLase $60 \mathrm{kHz}$ system uses a flat contact surface, while WaveLight FS200 uses a curved contact surface. ${ }^{3,7}$

The main purpose of this study was to compare the safety, efficacy, and predictability of femtosecond LASIK performed by two different laser suites.

\section{Materials and methods}

This retrospective, nonrandomized two-site study analyzed data of 28 patients with myopia who had undergone bilateral femtosecond LASIK. Patients were divided into two groups. Each group consisted of 14 patients (28 eyes). The first group had undergone femtosecond LASIK using IntraLase FS 60 femtosecond and the Visx Star S4 IR Excimer laser (Abbott Medical Optics Inc). The second group had undergone femtosecond LASIK using the WaveLight FS200 femtosecond and the EX500 Excimer laser (Alcon Laboratories, Inc.). Patients from the first group received a wavefront-guided (WFG) LASIK and the ones from the second group received a wavefront-optimized (WFO) LASIK. The latter were matched with patients selected in the first group based on age, sex, and preoperative mean refractive spherical equivalent (MRSE). The same surgeon (AM) performed all surgeries in both groups.
Patients included in the study were 18 years or older, had stable refraction, corrected distance visual acuity (CDVA) of 20/25 or better for each eye, no contraindications for LASIK, no history of previous ocular surgery, preoperative central corneal thickness $>500 \mu \mathrm{m}$, and a minimum residual thickness of $280 \mu \mathrm{m}$ with at least a $110 \mu \mathrm{m}$ femtosecond laserassisted flap, based on calculation simulation, and were able to return for follow-up on certain days and in certain months. In all eyes, the intended corneal flap thickness was $110 \pm 5 \mu \mathrm{m}$. In eyes treated with the IntraLase FS 60 system, 8.4-8.9 mm diameter flaps were created. All flaps had superior hinges with side-cut angles of $70^{\circ}$ and hinge angles of $50^{\circ}$. The bed laser pulse energy was $1.0 \mu \mathrm{J}$. The bed separation, and spot and line separations were $7 \mu \mathrm{m}$. In eyes treated with the WaveLight FS200, all flaps had superior hinges with side-cut angles of $70^{\circ}$ and hinge angles of $50^{\circ}$. The bed laser pulse energy was $0.69 \mu \mathrm{J}$. The bed separation, as well as spot and line separations were $7 \mu \mathrm{m}$.

Preoperative mean spherical equivalent (SE) was between -1.50 and $-8.5 \mathrm{D}$ and astigmatism was up to 1.75 D. All patients had standard preoperative evaluation, which included uncorrected distance visual acuity (UDVA), CDVA, manifest refraction, intraocular pressure, slit lamp examination, keratometry, corneal topography (Orbscan II2; Bausch \& Lomb Incorporated, Bridgewater, NJ, USA), wavefront aberrometry (Wavescan, Abbott Medical Optics Inc), tear function assessment, and dilated fundus examination. Patients were evaluated postoperatively at 1-day, 1-week, 1-month, and 6-month follow-up. Postoperatively, all patients were prescribed moxifloxacin hydrochloride $0.5 \%$ eyedrops (Vigamox, Alcon Laboratories, Inc.) and dexamethasone $0.1 \%$ eyedrops (Maxidex, Alcon Laboratories, Inc.) four times a day for 1 week. The study was approved by the ethics committees of the Hypervision Laser Centre and the Eye Day Clinic, Athens, Greece and followed the principles of the Declaration of Helsinki. Written informed consent was obtained from the patients.

\section{Statistical analysis}

Statistical analyses were conducted using Statistical Package for the Social Sciences statistical software (version 18.0; SPSS Inc., Chicago, IL, USA). Continuous variables are presented as mean and standard deviation. Quantitative variables are presented as absolute and relative frequencies. For the comparison of proportions, chi-square and Fisher's exact tests were used. For comparing the study variables between the two groups, the nonparametric Mann-Whitney test was used for non-normal variables and Student's $t$-test for normal variables. The main refractive measures included safety (safety index: mean postoperative CDVA divided by 
Table I Characteristics of the two study groups

\begin{tabular}{|c|c|c|c|}
\hline & Group I & Group 2 & $P$-value \\
\hline & $\overline{\text { Mean (SD) }}$ & $\overline{\text { Mean (SD) }}$ & \\
\hline Sex, male, n (\%) & $6(42.9)$ & $7(50.0)$ & $0.705^{\mathrm{a}}$ \\
\hline Age (years) & $34.0(8.3)$ & $31.8(9.3)$ & $0.51 \mathrm{I}^{\mathrm{b}}$ \\
\hline$K(D)$ & $43.8(1.3)$ & $43.3(1.6)$ & $0.193^{b}$ \\
\hline ССТ $(\mu \mathrm{m})$ & $558.9(37.6)$ & $54 I .4(58.8)$ & $0.092^{\mathrm{b}}$ \\
\hline
\end{tabular}

Notes: 'aisher's exact test; 'btudent's t-test. Group I: FS 60 kHz + Visx Star S4 IR (Abbott, Medical Optics, Inc., Santa Ana, CA, USA); Group 2: WaveLight FS200 (Alcon Laboratories, Inc., Fort Worth, TX, USA) + WaveLight EX500 (Alcon Laboratories, Inc.).

Abbreviations: $\mathrm{CCT}$, corneal thickness; K, keratometry; SD, standard deviation.

mean preoperative CDVA), efficacy (efficacy index: mean postoperative UDVA divided by mean preoperative CDVA), and predictability, (target SE within $\pm 0.5 \mathrm{D}$ of attempted correction). Differences in changes of UDVA, CDVA, and MRSE during the follow-up period between the two study groups were evaluated using repeated measures analysis of variance. The ranks in analysis of variance were used for MRSE due to their skewed distribution. All $P$-values reported are two-tailed. Statistical significance was set at 0.05 .

\section{Results}

A total of 56 eyes (28 patients) were included in the study. The mean age of patients was $34 \pm 8.3$ years in group 1 (42.9\% males) and $31.8 \pm 9.3$ years in group $2(50.0 \%$ males $)$. Characteristics of the two study groups are presented in Table 1. Preoperative MRSE was $-3.76 \pm 1.67 \mathrm{D}$ in the first group and $-4.57 \pm 2.2 \mathrm{D}$ in the second group $(P=0.206)$. There was no statistically significant difference in any baseline characteristic of patients in the two study groups.

\section{Efficacy}

At the 6-month follow-up, there was no significant difference in UDVA (decimal) between the two suites $(P=0.285)$ (Table 2). Also, $78.6 \%$ of eyes in group 1 and $92.9 \%$ of eyes in group 2 achieved UDVA of $20 / 20$ or better $(P=0.252)$ (Figure 1A and B; Table 3). Twenty-eight point six percent of eyes achieved UDVA of 20/16 or better in a week postoperatively in group 2 versus $21.4 \%$ in group $1(P=0.758)$.
Thirty-two point one percent of eyes achieved UDVA of $20 / 16$ or better in 1 month postoperatively in group 2 versus $25 \%$ in group $1(P=0.768)$. One eye in group 1 had microstriae with astigmatism resulting in UDVA of 20/30 and one patient had transient light sensitivity syndrome in group 1 , which lasted for 5 weeks after surgery and regressed with intensive topical corticosteroids.

\section{Safety and complications}

None of the patients of both groups lost lines of CDVA at the 6 months follow-up. Thirty-five point seven percent and 50\% in group 1 and group 2 , respectively, gained one line $(P=0.179)$ (Figure 1C). Thirty-nine point three percent of eyes in the first group and $35.7 \%$ in the second group were unchanged (Figure 1C). There were no intraoperative complications related to femtosecond laser-assisted LASIK flap creation.

\section{Predictability}

MRSE at 6 months follow-up was $0.05 \pm 0.26$ in group 1 and $0.07 \pm 0.24$ in group $2(P=0.495)$ (Table 4$)$. Twenty-five eyes in group $1(92.7 \%)$ and 27 eyes in group $2(96.3 \%)$ had MRSE within $\pm 0.5 \mathrm{D}$ at 6 months $(P>0.999)$ (Figures 1D, E and 2A). One eye in group 1 displayed change in MRSE of $>0.5 \mathrm{D}$ from 1 to 6 months postop, whereas no eye presented any change in group 2 .

\section{Refractive astigmatism}

The postoperative astigmatism at 1- and 6-month follow-up was similar between the two groups $(P>0.05)$ (Table 5) (Figure 2B and C). Regarding stability, refractive outcomes were stable at 6 months postoperatively (Figure 2D and E).

\section{Discussion}

This study evaluated the visual outcomes of 56 eyes that were treated with two different femtosecond laser suites. To our knowledge, no other study has compared the above refractive suites in terms of efficacy, safety, and predictability.

Table 2 Comparison of efficacy between the two study groups

\begin{tabular}{|c|c|c|c|c|c|c|c|c|}
\hline \multirow[t]{3}{*}{ Group } & \multirow{2}{*}{\multicolumn{2}{|c|}{$\begin{array}{l}\text { UDVA } \\
\text { I week (decimal) }\end{array}$}} & \multirow{2}{*}{\multicolumn{2}{|c|}{$\begin{array}{l}\text { UDVA } \\
\text { I month (decimal) }\end{array}$}} & \multirow{2}{*}{\multicolumn{2}{|c|}{$\begin{array}{l}\text { UDVA } \\
6 \text { months (decimal) }\end{array}$}} & \multirow{3}{*}{$\begin{array}{l}P \text {-value } \\
\text { I week versus } \\
6 \text { months }\end{array}$} & \multirow[t]{3}{*}{$P$-value ${ }^{b}$} \\
\hline & & & & & & & & \\
\hline & Mean & SD & Mean & SD & Mean & SD & & \\
\hline Group I & 1.00 & 0.15 & 1.01 & 0.15 & 1.06 & 0.15 & 0.001 & 0.285 \\
\hline Group 2 & 1.04 & 0.12 & 1.04 & 0.12 & 1.08 & 0.13 & 0.008 & \\
\hline$P$-value ${ }^{c}$ & 0.304 & & 0.293 & & 0.602 & & & \\
\hline
\end{tabular}

Notes: aP-value for time effect; ${ }^{b}$ effects reported include differences between the two groups in the degree of change in the particular variable (repeated measurements ANOVA); 'P-value for group effect. Group I: FS 60 kHz + Visx Star S4 IR (Abbott, Medical Optics, Inc., Santa Ana, CA, USA); Group 2: WaveLight FS200 (Alcon Laboratories, Inc., Fort Worth, TX, USA) + WaveLight EX500 (Alcon Laboratories, Inc.).

Abbreviations: ANOVA, analysis of variance; SD, standard deviation; UDVA, uncorrected distance visual acuity. 


\section{Uncorrected distance visual acuity}
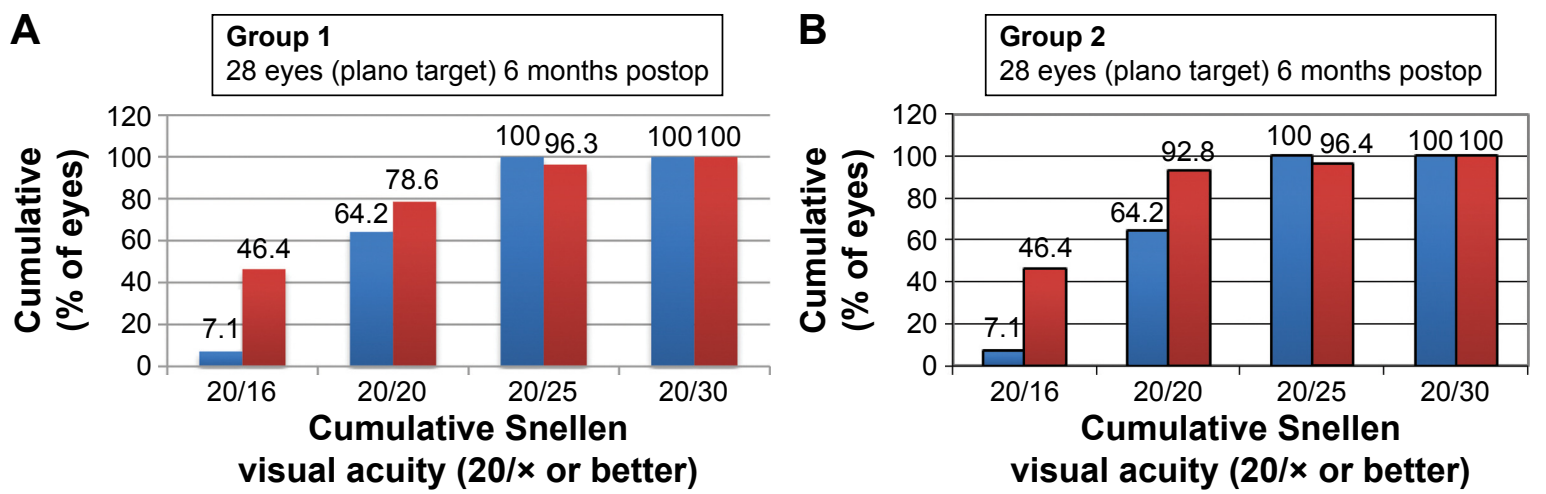

$\square$ Preop CDVA

Postop UDVA

C

Change in corrected distance visual acuity

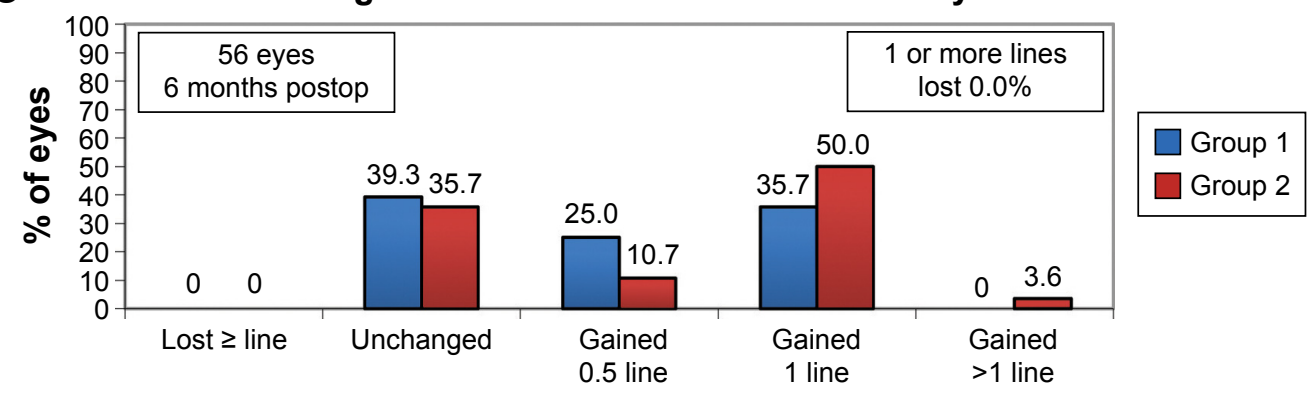

Change in Snellen lines of CDVA

Spherical equivalent attempted versus achieved
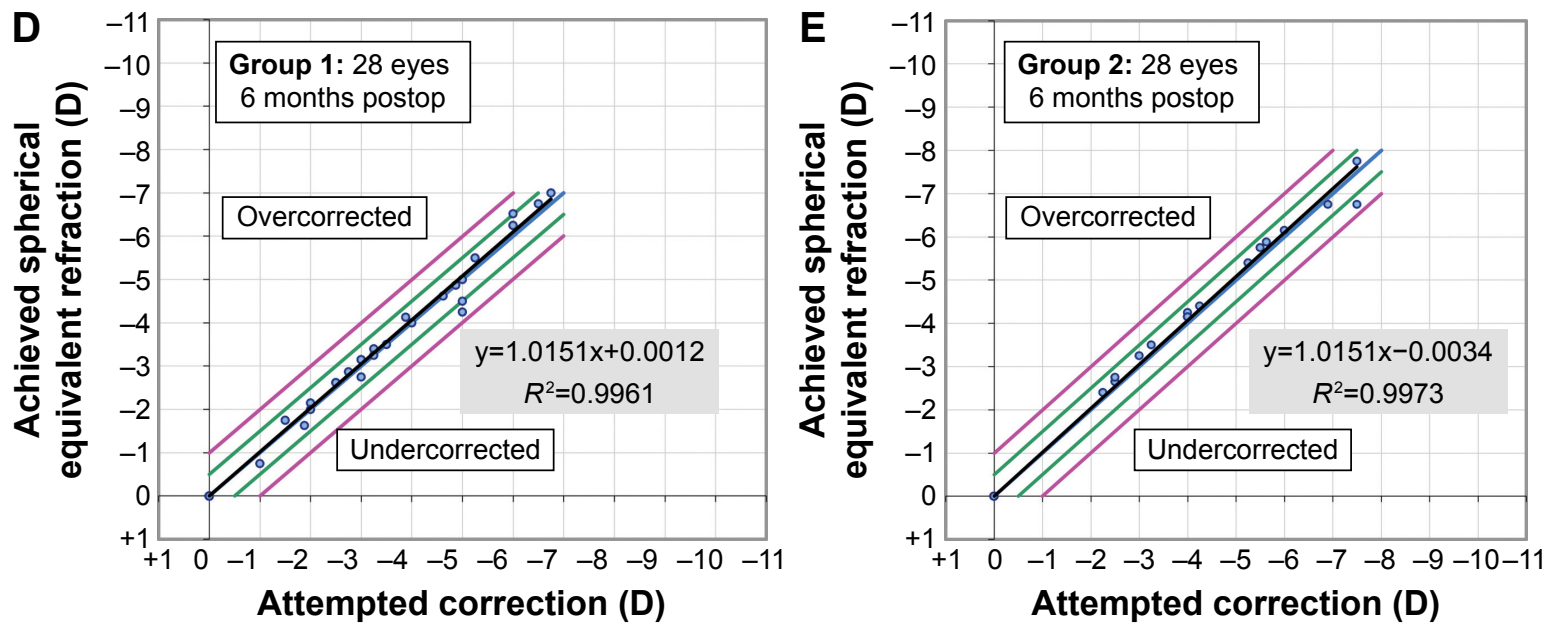

Figure I Efficacy and safety outcomes at 6 months (56 eyes).

Notes: Six-month postoperative (56 eyes) cumulative UDVA, group I (A); 6-month postoperative cumulative UDVA, group 2 (B); change in corrected distance visual acuity in both groups (C); attempted versus achieved SE in group I (D) and in group 2 (E). Group I: FS 60 kHz + Visx Star S4 IR (Abbott, Medical Optics, Inc., Santa Ana, CA, USA); Group 2: WaveLight FS200 (Alcon Laboratories, Inc., Fort Worth, TX, USA) + WaveLight EX500 (Alcon Laboratories, Inc.).

Abbreviations: CDVA, corrected distance visual acuity; SE, spherical equivalent; UDVA, uncorrected distance visual acuity; postop, postoperative.

At 6-month follow-up, $92.8 \%$ of eyes in group 2 and $78.6 \%$ of eyes in group 1 achieved a UDVA of $20 / 20$ or better. No eye lost lines of CDVA. The mean efficacy index at 6 months was $1.10 \pm 0.12$ in group 1 and $1.10 \pm 0.1$ in group 2 $(P=0.799)$. The mean safety index at 6-month follow-up was $1.10 \pm 0.10$ in group 1 and $1.10 \pm 0.09$ in group $2(P=0.407)$.
In a previous study, ${ }^{16,17}$ both IntraLase $60 \mathrm{kHz}$ and Visumax $500 \mathrm{kHz}$ produced comparable efficacy and predictability profiles for flap creation in LASIK. In another study by $\mathrm{Yu}$ and Manche, ${ }^{18}$ when comparing the $150 \mathrm{kHz}$ femtosecond group versus the $60 \mathrm{kHz}$ group, $94.5 \%$ and $85.2 \%$ of eyes, respectively, achieved a UDVA of $20 / 20$ 
Table 3 Efficacy comparison of the two study groups

\begin{tabular}{|c|c|c|c|}
\hline \multirow[t]{2}{*}{ Parameter } & \multirow{2}{*}{$\frac{\text { Group I }}{\%}$} & \multirow{2}{*}{$\frac{\text { Group } 2}{\%}$} & \multirow[t]{2}{*}{$P$-value ${ }^{a}$} \\
\hline & & & \\
\hline \multicolumn{4}{|l|}{ Efficacy (UDVA) } \\
\hline \multicolumn{4}{|l|}{ I week } \\
\hline $20 / 16$ or better & 21.4 & 28.6 & 0.758 \\
\hline $20 / 20$ or better & 78.6 & 92.9 & 0.252 \\
\hline \multicolumn{4}{|l|}{ I month } \\
\hline $20 / 16$ or better & 25.0 & 32.1 & 0.768 \\
\hline $20 / 20$ or better & 78.6 & 92.9 & 0.252 \\
\hline \multicolumn{4}{|l|}{6 months } \\
\hline $20 / 16$ or better & 46.4 & 46.4 & $>0.999$ \\
\hline
\end{tabular}

Notes: aPearson chi-square test. Group I: FS $60 \mathrm{kHz}+$ Visx Star S4 IR (Abbott, Medical Optics, Inc., Santa Ana, CA, USA); Group 2: WaveLight FS200 (Alcon Laboratories, Inc., Fort Worth, TX, USA) + WaveLight EX500 (Alcon Laboratories, Inc.).

Abbreviation: UDVA, uncorrected distance visual acuity.

or better in 6-month follow-up. However, in that study, the $60 \mathrm{kHz}$ and the $150 \mathrm{kHz}$ femtosecond systems showed similar predictability 12 months postoperatively. Also, in the same study, the FS200 femtosecond group had a better UDVA faster, which, according to the authors, is suggestive of a faster visual recovery. However, when using Bonferroni correction, the authors concluded that the difference in 1 week was not statistically significant. The authors suggest that a faster flap creation time leads to reduction in stromal cell damage and smoother flap interface allowing for more rapid healing.

In this study, the percentage of eyes that achieved UDVA of 20/16 or better in a month postoperatively in group 2 was greater than the percentage obtained in group 1. This is suggestive of a faster recovery in group 2, despite the fact that the difference in 1 week was not statistically significant in either group. Kymionis et $\mathrm{al}^{15}$ found the IntraLase $150 \mathrm{kHz}$ femtosecond laser to be comparable to the WaveLight FS200 system. We suggest that higher-energy lasers create smoother interface and less corneal damage, which means faster recovery. Therefore, our results are similar to those of previous studies that compared higher-energy lasers to lower-energy ones.
A recent meta-analysis ${ }^{9}$ that compared different types of FS lasers for LASIK showed that there is no statistically significant difference in the loss of $\geq 2$ Snellen lines of CDVA (safety) between different FS lasers and no statistically significant difference in the mean spherical equivalent within $\pm 0.5 \mathrm{D}$ of target refraction (predictability). However, IntraLase and FEMTO LDV were significantly better in the proportion of eyes within a UDVA of 20/20 or better (efficacy). Also, IntraLase and WaveLight SF200 had the least intraoperative complications, with the most frequently reported being diffuse lamellar keratitis and microstriae. IntraLase FS 60 kHz, Visumax, and WaveLight FS200 seldom had postoperative complications such as loss of suction, transient opaque bubble layer, and adhesions.

In this study, we had neither free flaps, irregular flaps, decentered flaps, and epithelial defects, nor complications ${ }^{19}$ such as opaque bubble layer. ${ }^{20}$ In the IntraLase group, we had only one patient with transient light sensitivity syndrome ${ }^{21,22}$ and an eye with microstriae. It is well known that if microstriae involve the visual axis, they can induce irregular astigmatism and decrease the CDVA. In our study, we had an eye with microstriae that induced astigmatism and decreased CDVA, which was treated by lifting the flap, hydrating, stretching, repositioning, and swelling it with hypotonic solutions. However, the above patients were among the first cases before making proper adjustments to the laser platform.

We used different ablation systems, the WFG and the WFO treatments. Previous studies ${ }^{23-25}$ that compared the visual outcomes of WFG versus WFO have evaluated the efficacy, safety, and predictability of both treatments, although Allegretto Wave Eye-Q $400 \mathrm{~Hz}$ was used instead of EX500 Excimer laser. In the study by $\mathrm{He}$ et $\mathrm{al},{ }^{23}$ on comparing the clinical outcomes of WFG LASIK versus WFO treatment, both treatments were able to correct myopia safely and effectively. However, WFG treatment offered significant advantages in terms of residual refractive error, uncorrected distance acuity, and contrast sensitivity. In another study, ${ }^{25}$

Table 4 Mean MRSE values at baseline and during follow-up for both study groups

\begin{tabular}{|c|c|c|c|c|c|c|c|c|}
\hline \multirow[t]{2}{*}{ Group } & \multicolumn{2}{|c|}{ MRSE at baseline } & \multicolumn{2}{|c|}{$\begin{array}{l}\text { MRSE at I month } \\
\text { follow-up }\end{array}$} & \multicolumn{2}{|c|}{$\begin{array}{l}\text { MRSE at } 6 \text { months } \\
\text { follow-up }\end{array}$} & \multirow[t]{2}{*}{$P$-value ${ }^{a}$} & \multirow[t]{2}{*}{$P$-value ${ }^{b}$} \\
\hline & Mean & SD & Mean & SD & Mean & SD & & \\
\hline Group I & -3.76 & 1.67 & 0.09 & 0.32 & 0.05 & 0.26 & $<0.001$ & 0.132 \\
\hline Group 2 & -4.57 & 2.2 & 0.13 & 0.26 & 0.07 & 0.24 & $<0.001$ & \\
\hline$P$-value ${ }^{c}$ & 0.206 & & 0.802 & & 0.495 & & & \\
\hline
\end{tabular}

Notes: ${ }^{\text {a }}$-value for change from baseline to 6 months; beffects reported include differences between the two groups in the degree of change in the particular variable (repeated measurements ANOVA); 'P-value for group effect. Group I: FS 60 kHz + Visx Star S4 IR (Abbott, Medical Optics, Inc., Santa Ana, CA, USA); Group 2: WaveLight FS200 (Alcon Laboratories, Inc., Fort Worth, TX, USA) + WaveLight EX500 (Alcon Laboratories, Inc.).

Abbreviations: ANOVA, analysis of variance; MRSE, mean refractive spherical equivalent; SD, standard deviation. 
A

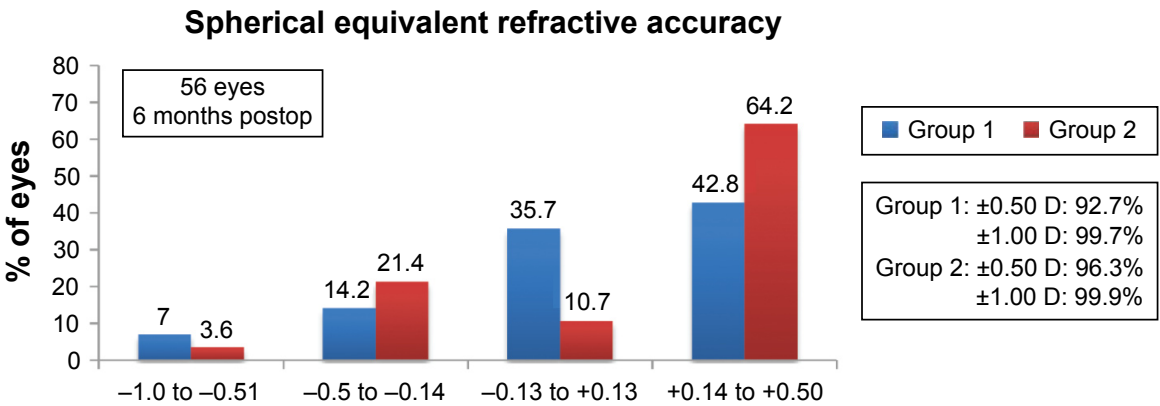

Postoperative spherical equivalent refraction (D)

Refractive astigmatism

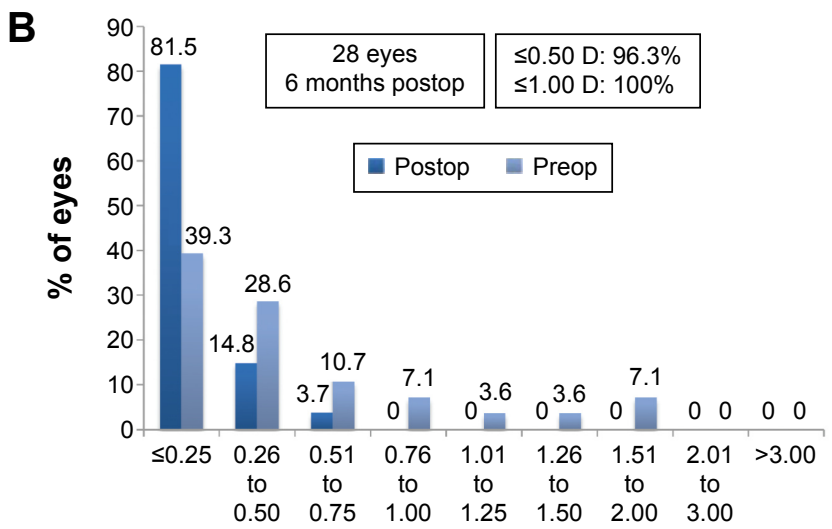

Refractive astigmatism (D)

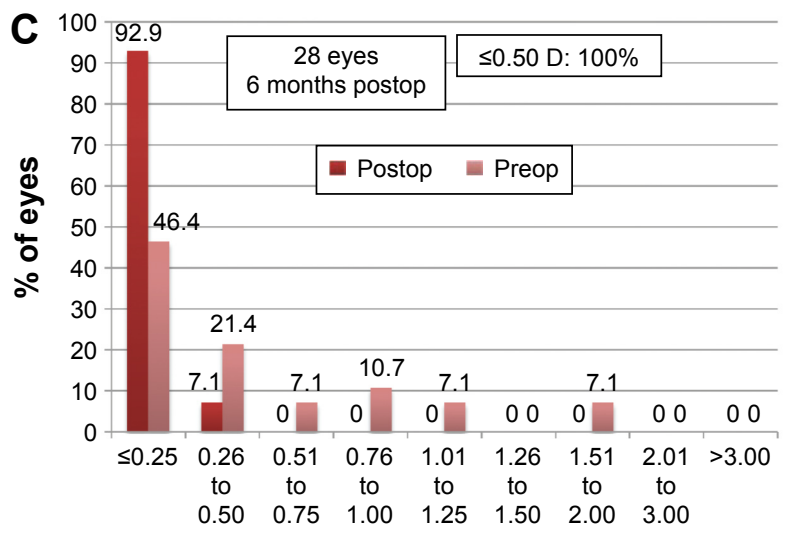

Refractive astigmatism (D)

Stability of spherical equivalent refraction
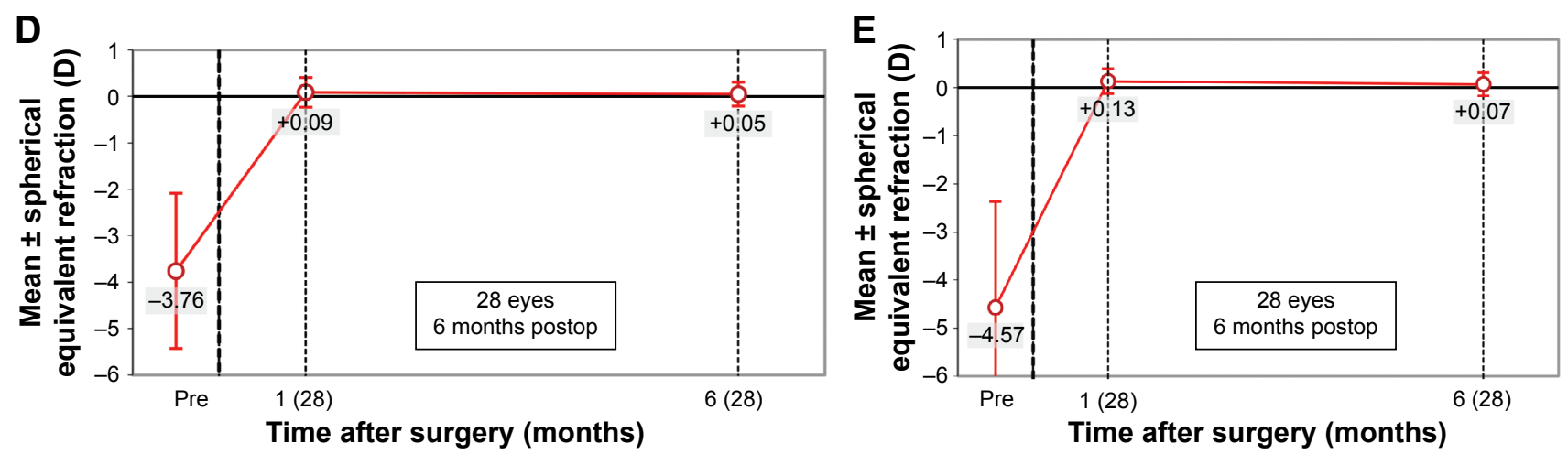

Figure 2 Predictability and stability at 6 months.

Notes: Six-month refractive accuracy (56 eyes) in both groups (A), refractive astigmatism in group I (B) and in group 2 (C), refractive stability in group I (D) and in group 2 (E). Group I: FS 60 kHz + Visx Star S4 IR (Abbott, Medical Optics, Inc., Santa Ana, CA, USA); Group 2: WaveLight FS200 (Alcon Laboratories, Inc., Fort Worth, TX, USA) + WaveLight EX500 (Alcon Laboratories, Inc.).

Abbreviations: preop, preoperative; postop, postoperative.

when comparing the visual outcomes of variable spot scanning ablation versus WFO using the same excimer lasers, both treatments were able to correct myopia safely and effectively and the same visual performance of eyes was recorded in either group. Finally, in another study, ${ }^{24} \mathrm{WFG}$ and WFO LASIK produced similar results in myopic patients. However, the WFG approach yielded gains in visual acuity, predictability, and high order aberrations.
In this study, both techniques showed comparative accuracy, predictability, safety, and stability. However, better UDVA in a month postoperatively in group 2 could be attributed to the faster ablation of the WaveLight EX500; being a fast laser, it has great advantage compared to Visx, enabling treatments of each diopter of myopia in 1.4 seconds (based on a $6.0 \mathrm{~mm}$ optical zone of treatment). Therefore, it may produce better visual outcomes by reducing stromal 
Table 5 Postoperative astigmatism at $I$ and 6 months for the two study groups

\begin{tabular}{|c|c|c|c|c|c|}
\hline & \multicolumn{2}{|c|}{ Group I } & \multicolumn{2}{|c|}{ Group 2} & \multirow[t]{2}{*}{$P$-value ${ }^{a}$} \\
\hline & $\bar{n}$ & $\%$ & $\bar{n}$ & $\%$ & \\
\hline \multicolumn{6}{|c|}{ Postoperative astigmatism at I month } \\
\hline$\leq 0.25$ & 17 & 60.7 & 16 & 57.1 & $>0.999$ \\
\hline $0.26-0.5$ & 10 & 35.7 & $\mathrm{II}$ & 39.3 & \\
\hline $0.5 \mathrm{I}-0.75$ & I & 3.6 & 1 & 3.6 & \\
\hline \multicolumn{6}{|c|}{ Postoperative astigmatism at 6 months } \\
\hline$\leq 0.25$ & 23 & 82.1 & 26 & 92.9 & 0.422 \\
\hline $0.26-0.5$ & 4 & 14.3 & 2 & 7.1 & \\
\hline $0.5 \mathrm{I}-0.75$ & 1 & 3.6 & 0 & 0 & \\
\hline
\end{tabular}

Notes: 'Fisher's exact test. Group I: FS $60 \mathrm{kHz}+$ Visx Star S4 IR (Abbott, Medical Optics, Inc., Santa Ana, CA, USA); Group 2: WaveLight FS200 (Alcon Laboratories, Inc., Fort Worth, TX, USA) + WaveLight EX500 (Alcon Laboratories, Inc.).

dehydration, flap shrinkage, sensitivity to eye movements, and patient fixation fatigue. ${ }^{26}$

Yet, there are certain limitations to this study. It is a retrospective, not a randomized eye-to-eye study. Changes in aberrations and contrast sensitivity are not reported. Besides, this study had a small sample size and a 6-month follow-up period. Therefore, we need larger studies with longer-term follow-up to detect discreet differences between the two laser suites.

In summary, in this study, the refractive and visual outcomes were similar between the two laser suites. Despite the shorter pulse duration, lower energy setting of the FS200 system, and the faster ablation of the Wavelight EX500 excimer laser, at a 6-month follow-up, there were no remarkable differences in efficacy, safety, and predictability between both groups. We suggest that WFG treatment may improve the final visual outcomes of group 1, as according to most studies, ${ }^{24,26-29}$ this treatment is slightly superior in terms of refractive outcomes, minimizing the induction of high order aberrations and improving contrast sensitivity. In the end, both laser suites resulted in excellent outcomes.

\section{Disclosure}

The authors report no conflicts of interest in this work.

\section{References}

1. Farjo AA, Sugar A, Schallhorn SC, et al. Femtosecond lasers for LASIK flap creation: a report by the American Academy of Ophthalmology. Ophthalmology. 2013;120(3):e5-e20.

2. Stonecipher K, Ignacio TS, Stonecipher M. Advances in refractive surgery: microkeratome and femtosecond laser flap creation in relation to safety, efficacy, predictability, and biomechanical stability. Curr Opin Ophthalmol. 2006;17(4):368-372.

3. Lubatschowski H. Overview of commercially available femtosecond lasers in refractive surgery. J Refract Surg. 2008;24(1): S102-S107.
4. Pietilä J. Flap Creation in Laser-Assisted in Situ Keratomileusis: From Microkeratome to Femtosecond Laser. Tampere: Tampere University Press; 2012.

5. Zhang Y, Chen YG, Xia YJ. Comparison of corneal flap morphology using AS-OCT in LASIK with the WaveLight FS200 femtosecond laser versus a mechanical microkeratome. J Refract Surg. 2013;29(5):320-324.

6. Kanellopoulos AJ, Asimellis G. Digital analysis of flap parameter accuracy and objective assessment of opaque bubble layer in femtosecond laser-assisted LASIK: a novel technique. Clin Ophthalmol. 2013;7: 343-351.

7. Mrochen M, Wüllner C, Krause J, Klafke M, Donitzky C, Seiler T. Technical aspects of the WaveLight FS200 femtosecond laser. J Refract Surg. 2010;26(10):S833-S840.

8. Kezirian GM, Stonecipher KG. Comparison of the IntraLase femtosecond laser and mechanical keratomes for laser in situ keratomileusis. J Cataract Refract Surg. 2004;30:804-811.

9. Huhtala A, Pietilä J, Mäkinen P, Uusitalo H. Femtosecond lasers for laser in situ keratomileusis: a systematic review and meta-analysis. Clin Ophthalmol. 2016;10:393-404.

10. Santhiago MR, Kara-Junior N, Waring GO. Microkeratome versus femtosecond flaps: accuracy and complications. Curr Opin Ophthalmol. 2014;25(4):270-274.

11. Sugar A. Ultrafast (femtosecond) laser refractive surgery. Curr Opin Ophthalmol. 2002;13(4):246-249.

12. Chen S, Feng Y, Stojanovic A, Jankov MR, Wang Q. IntraLase femtosecond laser vs mechanical microkeratomes in LASIK for myopia: a systematic review and meta-analysis. J Refract Surg. 2012; 28(1):15-24.

13. Zhang ZH, Jin HY, Suo Y, et al. Femtosecond laser versus mechanical microkeratome laser in situ keratomileusis for myopia: metaanalysis of randomized controlled trials. J Cataract Refract Surg. 2011;37(12): 2151-2159.

14. Durrie DS, Kezirian GM. Femtosecond laser versus mechanical keratome flaps in wavefront-guided laser in situ keratomileusis: prospective contralateral eye study. J Cataract Refract Surg. 2005;31(1): $120-126$.

15. Kymionis GP, Kontadakis GA, Naoumidi I, et al. Comparative study of stromal bed of LASIK flaps created with femtosecond lasers (Intralase FS 150, Wavelight Intralase FS 200) and mechanical microkeratome. Br J Ophthalmol. 2014;98(1):133-137.

16. Ang M, Mehta JS, Rosman M, et al. Visual outcomes comparison of 2 femtosecond laser platforms for laser in situ keratomileusis. J Cataract Refract Surg. 2013;39(11):1647-1652.

17. Rosman M, Hall RC, Chan C, et al. Comparison of efficacy and safety of laser in situ keratomileusis using 2 femtosecond laser platforms in contralateral eyes. J Cataract Refract Surg. 2013;39(7):1066-1073.

18. Yu CQ, Manche EE. Comparison of 2 femtosecond lasers for flap creation in myopic laser in situ keratomileusis: one-year results. J Cataract Refract Surg. 2015;41(4):740-748.

19. Santos AM, Torricelli A, Marino GK, et al. Femtosecond laser-assisted LASIK flap complications. J Refract Surg. 2016;32(1):52-59.

20. Kaiserman I, Maresky HS, Bahar I, Rootman DS. Incidence, possible risk factors, and potential effects of an opaque bubble layer created by a femtosecond laser. J Cataract Refract Surg. 2008;34(3): 417-423.

21. Stonecipher KG, Dishler JG, Ignacio TS, Binder PS. Transient light sensitivity after femtosecond laser flap creation: clinical findings and management. J Cataract Refract Surg. 2006;32(1):91-94.

22. Munoz G, Albarran-Diego C, Sakla HF, Javaloy J, Alio JL. Transient light-sensitivity syndrome after laser in situ keratomileusis with the femtosecond laser incidence and prevention. J Cataract Refract Surg. 2006;32(12):2075-2079.

23. He L, Liu A, Manche EE. Wavefront-guided versus wavefrontoptimized laser in situ keratomileusis for patients with myopia: a prospective randomized contralateral eye study. Am J Ophthalmol. 2014; 157(6):1170-1178. 
24. Sales CS, Manche EE. One-year outcomes from a prospective, randomized, eye-to-eye comparison of wavefront-guided and wavefront-optimized LASIK in myopes. Ophthalmology. 2013;120(12): 2396-2402.

25. Khalifa M, Mossallam E, Massoud T, Shaheen S. Comparison of visual outcomes after variable spot scanning ablation versus wavefrontoptimised myopic LASIK. J Refract Surg. 2015;31(1):22-28.

26. Han DC, Chen J, Htoon HM, Tan DT, Mehta JS. Comparison of outcomes of conventional WaveLight $\left({ }^{\circledR}\right)$ Allegretto Wave $\left({ }^{\circledR}\right)$ and Technolas $\left({ }^{\circledR}\right)$ excimer lasers in myopic laser in situ keratomileusis. Clin Ophthalmol. 2012;6:1159-1168.
27. Brint SF. Higher order aberrations after LASIK for myopia with Alcon and WaveLight lasers: a prospective randomized trial. J Refract Surg. 2005;21(6):S799-S803.

28. Moshirfar M, Betts BS, Churgin DS, et al. A prospective, randomized, fellow eye comparison of WaveLight ${ }^{\circledR}$ Allegretto Wave ${ }^{\circledR}$ Eye-Q versus VISX CustomVue ${ }^{\mathrm{TM}}$ STAR S4 IR ${ }^{\mathrm{TM}}$ in laser in situ keratomileusis (LASIK): analysis of visual outcomes and higher order aberrations. Clin Ophthalmol. 2011;5:1339-1347.

29. Feng Y, Yu J, Wang Q. Meta-analysis of wavefront-guided vs wavefront-optimized LASIK for myopia. Optom Vis Sci. 2011;88(12): 1463-1469.
Clinical Ophthalmology

\section{Publish your work in this journal}

Clinical Ophthalmology is an international, peer-reviewed journal covering all subspecialties within ophthalmology. Key topics include: Optometry; Visual science; Pharmacology and drug therapy in eye diseases; Basic Sciences; Primary and Secondary eye care; Patient Safety and Quality of Care Improvements. This journal is indexed on

\section{Dovepress}

PubMed Central and CAS, and is the official journal of The Society of Clinical Ophthalmology (SCO). The manuscript management system is completely online and includes a very quick and fair peer-review system, which is all easy to use. Visit http://www.dovepress.com/ testimonials.php to read real quotes from published authors. 